\title{
Educating to bridge the knowledge gap: hybrid management undergraduate education 1985-1995
}

\author{
Alan Gillies and Tony Greenwood \\ Lancashire Business School \\ Preston, Lancashire. Great Britain. Tel +441772893650 \\ E-Mail i.m.research@UCLAN.AC.UK.
}

\begin{abstract}
Many companies report a knowledge gap between users of information systems and their developers. In the 1980s, this led to the popularity of the concept of hybrid managers with a working knowledge of business and computing. A number of degree courses were established to provide graduates educated for this role.

Initial response from UK industry and Government were enthusiastic. In 1985, The IT Institute (ITI) was established at the University of Salford with $£ 1.5$ million in sponsorship from the Government and Industry. In practice, many of the principles had been established in the earlier BIT degree programme at Lancashire Business School. A Government report in 1987 recommended the establishment of 20 other similar establishments. In 1988, the Institute won an award for the quality of training provided for ICL managers based upon its expertise in hybrid management education.

Since then, a number of factors have led to a decline in hybrid management undergraduate education. Indeed, the term 'hybrid manager' has fallen into disrepute.

This paper argues that the need for this type of education is greater than ever. It presents a SWOT-style analysis of hybrid management education programmes, based upon the authors' collective experience of fifteen years teaching at the ITI and the Department of Business Information Management at the Lancashire Business School.
\end{abstract}

\section{THE PROBLEM: THE KNOWLEDGE GAP}

Over the years, a range of authors have commented on a 'knowledge gap' between technical staff and general managers. The term 'knowledge gap' comes from the Price Waterhouse IT reviews (Price Waterhouse $(1990,1992))$.

Gillies (1992) highlights problems in companies exhibiting a clear 'gap' between IT developers and users. Case studies of six companies demonstrated that users and developers did not appreciate the others' points of views when considering what was required of 
information systems within a company. The knowledge gap is one manifestation of a culture gap.

In spite of this problem being well established, it does not seem to be diminishing in practice. This may be attributed to factors which serve to reinforce current problems. Two principal factors are the pace of technological change and the hierarchical structures within companies. The pace of technological change is accelerating; this encourages the view that only specialist technologists can deal with the new technologies as they come along. The hierarchies within organisations tend to separate technical people into their own ghetto areas. Working within their own internal organisations, they are insulated from the daily needs of the business.

This insulation has been enshrined within the practice of outsourcing where the IT expertise is placed outside the organisation altogether. The growth of outsourcing reflects at least in part the increasing isolation of IT departments from their own organisations, as well as a failure on the part of senior management of the value of having IT staff with a knowledge of the companies' business. It is frequently acknowledged that IT staff need business knowledge (Jones et al, 1995) but this need not in itself lead to more than an acknowledgment of business issues in IT decision making.

\section{THE SOLUTION: HYBRID MANAGERS}

Given the foregoing, it is helpful to see if we can move beyond the idea of an expert in a particular field developing new knowledge and using this to do their job better. Instead we investigate the case of someone with management expertise who is able to work in both business and technical scenarios. The world view of such a person would not be limited by their technical or business background. Rather, they would be a hybrid. Earl (1989) describes hybrid managers as: "people with strong technical skills and adequate business knowledge, or vice versa ... able to work in user areas doing a line or functional job, but adept at developing and implementing IT application ideas," (quoted in Earl \& Skyrme, 1992). This hands-on role can be compared with descriptions of Chief Information Officers (CIO) such as "the overall authority for policy, technology and performance standards related to information resource management and applications, as well as for the development and management of interdepartmental or corporate systems and resources" (Borbely, 1989, quoted in Karake, 1995)

We will see later that CIOs have the characteristics of a hybrid manager and that the CIO role could be played by a hybrid, but the differences in the above definitions suggest that a hybrid manager does not necessarily have to be involved in strategic decision making. Indeed, the development of hybrid tactics for addressing previously identified strategic issues may be an important means by which hybrid managers add value to their organisations.

\subsection{Characteristics of the hybrid manager}

Earl and Skyrme (1992) report the work of Lyons (1985) and Vaccaro (1989) in identifying the personality characteristics of data processing professionals. Using the Myers-Briggs framework, described in Lyons(1985), Earl \& Skyrme hypothesise that the temperaments of hybrids could be "visionaries" or "catalysts". The term "visionary" is used to describe people with distinctively strong intuition combined with logical thinking abilities who are therefore 
creative and seek recognition of their competence. "Catalysts" have intuition and take decisions based on feelings more than logic. They are good at building alliances and coalitions, having excellent communication skills.

Murphy et al (1992) investigated the role of group leaders and found (under laboratory conditions) that "the leader's technical knowledge or expertise contributed to group performance only if the leader was both trained and directive." (Wright, 1996) This broadens the discussion by introducing characteristics necessary to the carrying out of roles which the hybrid manager is likely to undertake but to analyse this more fully it would be necessary to distinguish between characteristics which are distinctive to hybrids and characteristics which arise from roles whether or not they are being played by hybrids. We do not pursue this further in the present study.

\subsection{Roles of the hybrid manager in organisations}

Scarbrough (1993) focuses on the management of expert groups, seeing hybrid managers involved in the integration of technical and business management at the strategic level whereas multidisciplinary teams of monoglots function at the operational level. Lee et al (1995) discuss the importance of strategic decision makers understanding and making the best use of "the intricate synergism between information technology and organisational structure." It follows from Earl's (1989) description of hybrid managers, quoted above, that the hybrid will require other expertise in order to function fully, drawn from business or technical fields as appropriate. This expertise could be obtained from groups managed by the hybrid of from groups in which the hybrid participates, possibly in a leadership capacity.

A third type of relationship could be described as the policing role. In the United Kingdom, the Department of Social Security has established Data Administration Units within its various agencies. The data administrators devise and enforce data standards, and must communicate fully with technical and business practitioners. The staff are drawn from business areas but receive technical training in, for example, data modelling (Clare \& Greenwood, 1996) and IS project management (Greenwood \& Rynn, 1996)

The decentralising of MIS services creates a role for hybrid managers (Brown \& Magill, 1994) as information systems functions are carried out within the line management structure of business areas. For example, the MIS services department at the University of Central Lancashire was temporarily dismembered because of a lack of perceived business involvement in the centralised service. It was later re-formed in order to overcome a perceived lack of critical mass amongst development staff but during the dismembered period the development staff acquired valuable business knowledge to the extent that the technical managers now adopt a more hybrid stance.

\subsection{Required skills}

Earl \& Skyrme (1992) echo the SSADM (Downs, Clare \& Coe, 1988) project structure in examining technology, business and management skills. They add "organisational intelligence" to this list, covering such matters as appreciating the culture of the organisation and knowing who can provide help and support. As noted above, though, it aids clarity if specific hybrid competencies are differentiated from general role-related competencies.

Technology competencies include the ability to recognise IT opportunities and planning and managing IT projects including the selection and management of internal or external 
providers. Hybrids also require business confidence, understanding the business of the organisation and its divisions and being able to make a business case for required applications. And they need management skills, particularly the ability to communicate effectively.

Jones et al (1995) take an empirical approach and examine satisfaction with the CIO mentioning as good practice the example of "General Food's former IS manager who reportedly divided his time equally between running the IS organisation, communicating with General Foods executives about the business, and learning about opportunities and threats outside the company" though we note that in order to qualify as a hybrid he would have had to integrate these activities. Jones et al examine three areas: general management abilities, communication abilities, and knowledge / commitment to the business.

We see from these studies that organisations demand IS managers with a high level of business and management competence alongside their technical ability. The education of potential holders of such hybrids forms the main theme of this paper.

\section{THE EDUCATION OF HYBRID MANAGERS}

With such issues in mind, the Business Information Technology degree was launched at the Lancashire Business School in 1984. Two years later, one of the principal architects of that course moved to the IT Institute at Salford to run the BSc in Information Technology. Both institutions have followed their undergraduate programmes with postgraduate programmes to transfer the benefits to postgraduate level. Other institutions have developed programmes from similar starting points (for example Ruohonen, 1992).

The Lancashire and Salford courses set out to produce graduates with a profile which enabled them to apply technology within businesses. They sought to overcome the technological limitations of existing business graduates and to provide technology graduates with an appreciation of business needs.

Crucial to both courses was the need to address issues at the crossover between business and technology, rather than provide a joint honours in business and computing. In order to do this, distinctive teaching methods were employed:

- Team projects were used with outside commercial clients. In the Salford case, multiyear teams were used and different roles established for different years of students. At Lancashire, postgraduate students also took part in intensive residential simulations of business scenarios in which students had to play a hybrid role.

- At Salford, basic IT skills were taught through 'solo courses': computer based training courses which provided basic skills in areas such as word processing, spreadsheets, database design.

- Presentation skills were emphasised, with both team and individual presentations forming part of the courses. Experiences gained when preparing sandwich students for placement was used in promoting the development of wider enterprise skills.

In the next section we shall consider a SWOT analysis of these courses. 


\section{ANALYSIS OF HYBRID MANAGEMENT EDUCATION}

\subsection{Strengths of the courses}

These courses have a number of clear strengths:

- These courses have some of the highest graduate employment rates in the UK, and noticeably higher than comparable courses in computing or business alone

- The courses have enjoyed a high degree of industrial support, for example $\mathfrak{£ 1 M}$ initial funding at Salford from the Government and industry. Salford and Lancashire have enjoyed ongoing support through sponsorship, work placements, projects, joint curriculum development initiatives and external examiners drawn from industry.

- The courses are characterised by a diverse student population with a high proportion of mature students and a high percentage of female students for a technology-based course.

- The students develop particular strengths in problem-solving, team working and presentation and communication skills.

- Course teams have worked towards addressing problems of assessing skills development alongside traditional academic discourse.

-

\subsection{Course weaknesses}

The courses do have some distinct weaknesses, however, including:

- The courses are high cost, due to the needs to provide up to date technology. In addition, many of the more innovative teaching ideas are staff-intensive. One residential simulation at Lancashire involves up to seven staff working with twenty students.

- The interdisciplinary nature of the degree has led some to question the academic depth of the degree as a whole. This criticism however can be levelled at any joint honours programme, increasingly as credit accumulation schemes have proliferated. The postgraduate course at Lancashire is a conversion course, so as with all conversion courses the derivation of the academic value is open to misunderstanding.

- The dependence upon industrial collaboration renders these courses sensitive to external economic conditions. It can lead to ethical dilemmas about whether all offers of assistance are appropriate, and debate surrounding the extent to which assessment can be based on performance in the workplace given the diversity of placement experiences..

\section{$\bullet$}

\subsection{Opportunities}

The courses are now well established. They have survived the worst excesses of student expansion in the early 1990s. There are now a number of opportunities available:

- The need for hybrid managers is greater than ever. Successful graduates now offer evidence of long term benefits of recruiting from these courses.

- The increasingly difficult financial environment for students makes the courses attractive with opportunities for earning during a sandwich year or vacation placements. In addition, the good prospects of employment enhance their financial attractiveness.

- The increasing role of computers in daily life and publicity for subjects such as the Internet is increasing awareness of the technology and demonstrating its broader appeal than traditional computing 


\subsection{Threats to the courses}

Some of the opportunities also provide potential threats.

- The general economic climate makes expensive courses less attractive to the Government. In addition, the increasing cost of being a student may well put students off higher education altogether.

- Departments running courses such as these tend to be penalised in research selectivity exercises where pure subjects tend to do better.

- The increase in modularisation makes the teaching of a genuinely hybrid course as opposed to a joint honours programme more difficult. It also promotes cheaper but lower quality joint programmes put together from existing computing and business programmes with little thought for course coherence or crossover issues.

\section{REVIEW OF THE PAST AND LESSONS FOR THE FUTURE}

The concept of a hybrid manager frequently arises in IS and business literature. Indeed, the problems addressed are not exclusively related to IS situations. Courses aimed at developing hybrid managers are in demand and produce students who meet the objectives for the courses and have good employment prospects. The perceived lack of academic depth is a significant criticism, particularly where funding for courses depends on sources additional to students' course fees and where attempts are made at cross-fertilisation between research and teaching.

It is important therefore to focus on what value is added by the hybrid manager. Recalling Earl's (1989) description: "people with strong technical skills and adequate business knowledge, or vice versa ..." the value does not come from the technical or business knowledge added to a manager from the opposite camp. The value comes from the hybridisation itself: the development of a third world-view which enables the hybrid to make a distinctive contribution to the business organisation.

As programmes for hybrid managers develop further, it will be necessary to concentrate on facilitating the development of the individual student. This is good practice in any case but is particularly significant in the hybrid context. Curricula which focus on the content itself cannot deliver genuinely hybrid managers. It is plain from the literature and from experience that the hybrid's distinctive contribution is a way of thinking.

\section{REFERENCES}

Borbely, J. (1989) Chief information officers: What's in a title?, Online, 12, 91-93

Brown, C.V. \& Magill, S.L., (1994) Alignment of the IS functions within the enterprise toward a model of antecedents, MIS Quarterly, 18, 371-403

Clare, P. \& Greenwood, A.R., (1996) Introduction to data modelling, University of Central Lancashire (unpublushed)

Downs, E., Clare, P. \& Coe, I. (1988) Structured systems analysis and design method: applications and context, Prentice Hall, Hemel Hempstead.

Earl, M.J. \& Skyrme, D.J., (1992) Hybrid managers - what do we know about them?, Journal of information systems, 2, 169-187 
Earl, M.J., (ed.) (1989) Management strategies for information technology, Prentice-Hall, Hemel Hempstead.

Gillies (1992) Software Quality Journal

Greenwood, A.R. \& Rynn, A.P. (1996) Introduction to project management, University of Central Lancashire (unpublished)

Jones, M.C., Taylor, G.S. \& Spencer, B.A., (1995) The CEO/CIO relationship revisited: an empirical assessment of satisfaction with IS, Information \& Management, 29, 123-130

Karake, Z.A. (1995) The management of information technology, governance, and managerial characteristics, Information Systems Journal, 5, 271-284

Lee, A., Cheng, C.H. \& Chadha, G.S., (1995) Synergism between information technology and organisational structure - a managerial perspective, Journal of Information Technology, 10, 37-43

Lyons, M.L., (1985) The DP psyche, Datamation, 31, August, 103-110

Murphy, S.E., Blyth, D. \& Fielder, F.E., (1992), Cognitive resources theory and the utilisation of the leader's and group members' technical competence, Leadership Quarterly, 3, 237 55

Price Waterhouse (1990) IT review

Price Waterhouse (1992) IT review

Ruohonen, M.J., (1992) Hybrid managers for the corporation of the 1990s - educational implications, IFIP Transactions A - Computer science and technology, 17, 49-58

Scarbrough, H. (1993) Problem-solutions in the management of information-systems expertise, Journal of Management Studies, 30, 939-955

Vaccaro, A.J., (1989) Personality clash, Personnel Administrator, 33, 88-92

Wright, P., (1996) Managerial Leadership, Routledge, London.

\section{BIOGRAPHY}

Alan Gillies is Professor of Information Management at the University of Central Lancashire. He gained his $\mathrm{PhD}$ in 1992 and his professorship in 1994. He has published widely and his research interests include medical audit and software quality management. He is also computing adviser for postgraduate medical education at Oxford University.

Tony Greenwood is currently Senior Lecturer in Decision Support Systems at the University of Central Lancashire and is course leader of the MSc Business Administration (Information Technology) conversion course for potential hybrid managers. Since 1982 he has taught at all levels in the education system and spent three years as a computer programmer. His research interests include data administration, and the economics of information management. 